\title{
DNA damage checkpoint adaptation genes are required for division of cells harbouring eroded telomeres
}

\author{
Sofiane Y. Mersaoui, Serge Gravel, Victor Karpov, and Raymund J. Wellinger* \\ Dept of Microbiology and Infectious Diseases, Faculty of Medicine and Health Sciences, Université de Sherbrooke, 3201, Rue Jean \\ Mignault, Sherbrooke, J1E 4K8, Canada. \\ * Corresponding Author: Raymund J. Wellinger, Tel: +1 8198218000 ext 75214; E-mail: Raymund.Wellinger@Usherbrooke.ca
}

\begin{abstract}
In budding yeast, telomerase and the Cdc13p protein are two key players acting to ensure telomere stability. In the absence of telomerase, cells eventually enter a growth arrest which only few can overcome via a conserved process; such cells are called survivors. Survivors rely on homologous recombination-dependent mechanisms for telomeric repeat addition. Previously, we showed that such survivor cells also manage to bypass the loss of the essential Cdc13p protein to give rise to Cdc13-independent (or capindependent) strains. Here we show that Cdc13-independent cells grow with persistently recognized DNA damage, which does not however result in a checkpoint activation; thus no defect in cell cycle progression is detectable. The absence of checkpoint signalling rather is due to the accumulation of mutations in checkpoint genes such as RAD24 or MEC1. Importantly, our results also show that cells that have lost the ability to adapt to persistent DNA damage, also are very much impaired in generating cap-independent cells. Altogether, these results show that while the capping process can be flexible, it takes a very specific genetic setup to allow a change from canonical capping to alternative capping. We hypothesize that in the alternative capping mode, genome integrity mechanisms are abrogated, which could cause increased mutation frequencies. These results from yeast have clear parallels in transformed human cancer cells and offer deeper insights into processes operating in pre-cancerous human cells that harbour eroded telomeres.
\end{abstract}

doi: $10.15698 /$ mic2015.10.229

Received originally: 21.04.2015;

in revised form: 14.08 .2015 ,

Accepted 17.08.2015,

Published 21.09.2015.

Keywords: telomeres, DNA damage checkpoints, chromosome capping.
Abbreviations:
ALT - alternative lengthening of telomeres,
$D S B$ - double strand break,
$H R$ - homologous recombination,
$\mathrm{HU}$ - hydroxyurea,
TRF - terminal restriction fragment, ts - temperature sensitivity, wt - wild type.

\section{INTRODUCTION}

Telomeres are essential for genome stability in all organisms with linear chromosomes; they play multiple roles in chromosome end protection, chromosome end replication and distinguishing chromosome ends from double strand breaks (DSBs) [1, 2]. Indeed, chromosome ends and DSBs superficially share a great deal of similarity as both are physical ends of DNA molecules. However, functional telomeres do not activate checkpoints and they are not subjected to DNA repair activities such as homologous recombination (HR) or end-to-end fusions [3, 4]. These features are provided by the unique structures and organization of the nucleoprotein complexes located at the ends of chromosomes $[5,6]$. Telomere structure and the molecular functions required for the above activities are also highly conserved, suggesting a common evolutionary origin. Telomeric DNA consists of short tandem DNA repeats, which generally create a G-rich strand that makes up the $3^{\prime}$ end of the chromosome. This strand also protrudes beyond the 5 ' end, forming a single stranded "G-tail" [7-9].

Chromosomes of Saccharomyces cerevisiae cells share these features and serve as an excellent model for studying telomere biology. There is an approximately $300 \mathrm{bps}$ double-stranded portion and a short single-stranded DNA portion of characteristic repeats at each chromosome end. These repeats are associated with specialized proteins that are essential for telomeric functions [1]. Specifically, telomeric capping in yeast is assured by a heterotrimeric complex composed of Cdc13p, Stn1p and Ten1p (the CSTcomplex; [1, 10-13]. Of these, Cdc13p specifically recognizes a short telomeric G-rich DNA substrate that can be the terminal G-tail and all three genes are essential. Hypomorphic alleles of $C D C 13$ exist and the $c d c 13-1$ allele, for example, confers temperature sensitivity (ts) to cells [14]. In cells with the $c d c 13-1$ allele that are incubated at restrictive temperatures $\left(>26^{\circ} \mathrm{C}\right)$, the C-rich strand of telomeric 
DNA is degraded, yielding extensive single-stranded DNA that can reach into subtelomeric DNA [15]. These ends become recognized as sites of DNA damage which triggers a robust Rad9-dependent cell-cycle checkpoint response and, eventually, cell death [13]. Cdc13p is also involved in allowing the complete replication of telomeres by recruitment of telomerase to telomeres [16].

Telomerase is the ribonucleoprotein that elongates telomeres during S-phase to counteract the shortening of telomeric DNA that occurs due to the 'end replication problem' [17-19]. A loss of telomerase leads to progressive telomere shortening, the so-called "ever shorter telomeres", or "EST" phenotype and a concomitant loss of the telomeric capping function [20-22]. Upon outgrowth of such cultures, the majority of cells ceases to divide after approximately 60-80 generations.

However, a small proportion of cells can regain the ability to divide and to maintain chromosome ends by telomerase-independent mechanisms; these cells are called survivors $[1,23]$. There are two major types of survivors which have one of two different arrangements of telomeric and subtelomeric DNA [24]. In type I survivors, a complex subtelomeric repeat element called $\mathrm{Y}^{\prime}$ spreads to all telomeres and only a very short telomeric repeat tract remains. Type II survivors on the other hand are defined by the presence of very long and heterogeneous telomeric repeat tracts [24]. These two types of cells can also be distinguished by the genetic requirements for the pathways involved [25]. Survivor cells still require Cdc13p-mediated chromosome capping, but $\mathrm{Cdc} 13$-independent survivors can be generated [26-28]. These latter cells do grow without the canonical organization of chromosomal ends; their telomeres yield a new pattern of terminal restriction fragments (TRFs) with a complete absence of discrete bands. Moreover, there is a high amount of telomeric and subtelomeric single-stranded DNA at chromosomal ends in Cdc13-independent survivors [28]. Previous evidence also suggests that telomeres in these cells essentially are elongated and maintained by HR mechanisms [28, 29]. Finally, cell growth without the capping protein Cdc13p is possible if genes involved in DSB processing (EXO1, SGS1) and certain checkpoint genes (RAD9, RAD24) are deleted simultaneously [29].

It has been speculated that particularly type II survivor yeast cells resemble human cancerous cells that replenish their telomeric repeat DNA via alternative telomeraseindependent mechanisms (alternative lengthening of telomeres, or ALT), [30, 31]. A commonality between yeast survivor and human ALT cells is that both are thought to amplify their telomeric DNA through recombinationdependent DNA replication [32]. This probably occurs through a mechanism involving extrachromosomal circular DNA containing telomeric repeat sequences [28, 33]. However, in virtually all human transformed cells, genomic integrity mechanisms are severely hampered and cells divide with ongoing genomic instability [34].

Here we show that Cdc13-independent survivor cells (cap-independent cells) do grow even though DNA damage foci can be observed to persist on telomeres. However, this apparent damage does not result in checkpoint signalling or cell cycle arrest. Our results show that this is because the Mec1-branch of the damage signalling pathway was abrogated via mutations in central checkpoint genes, mainly $R A D 24$ or MEC1. We also report that CDC5, PTC2 and TID1 are required for the initial generation of capindependent cells. Mutations in either of these genes significantly reduce the ability of survivor cells to overcome the loss of Cdc13p and resume growth. These results therefore reveal intriguing similarities between yeast cells dividing in the absence of $\mathrm{Cdc} 13 \mathrm{p}$ and human cancerous ALT-cells. Both display absence of cell division controls and continued cell divisions, despite ongoing telomere instability. We therefore hypothesize that this yeast system represents a useful tool for investigating the early phases of human cancerous cell growth.

\section{RESULTS}

Permanent detection of telomeric DNA damage but no checkpoint activation in Cdc13-independent survivors

Previous analyses of telomeres in Cdc13-independent survivors showed that their TRFs are extremely heterogeneous in length (see Fig. S1, lanes 8-10; and [28]). In order to obtain a more precise assessment of the terminal sequences on their chromosomes, we cloned and sequenced 17 independent terminal DNA fragments. 10 of those 17 harboured potentially functional telomeric repeat tracts (> 50 bps of repeat DNA), one had a critically short tract (35 bps) and six had tracts that were too short for even a single binding site for Rap1p, the major yeast protein binding double-stranded telomeric repeat tracts [1]. In fact, two of the 17 clones had no detectable telomeric G-rich sequences and ended with a subtelomeric $Y^{\prime}$ element (Fig. 1A).

Cells with such short or absent telomeric repeat tracts and potentially exposed single-stranded $Y^{\prime}$-DNA at chromosome ends display a strong DNA damage checkpoint [35]. We therefore verified whether the DNA damage checkpoint was activated in Cdc13-independent survivor cells, by assessing the level of phosphorylation of Rad53p, a major DNA damage checkpoint effector kinase in budding yeast ([36]; Fig. 1B). Rad53p migrates as a single discreet band in unperturbed growing cells, while DSBs caused by the addition of the radiomimetic phleomycin (a derivative of bleomycin) causes DNA damage checkpoint activation and robust phosphorylation of Rad53p as detected in the form of a retarded Rad53p band (Fig. 1B, lane 2). In Cdc13independent survivors, no phosphorylated Rad53p is detected in unperturbed cells and phleomycin addition only causes a very partial retardation of Rad53p, as if only a partial phosphorylation was possible (Fig. 2B, lanes 5, 6).

Similar results were obtained when phosphorylation of the checkpoint effector kinase Chk1p was assessed (Fig. S2). DNA damage, once detected, causes the activation of two sensor kinases, namely Mec1p and Tel1p (ATR and ATM in mammals [37, 38]), and phleomycin induced damage is sensed mainly via Mec1p. We thus reasoned that the very partial Rad53p phosphorylation detected in Cdc13independent survivors could be due to a loss of the Mec1 
A

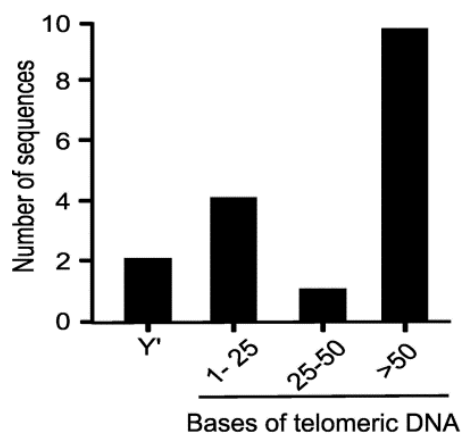

B

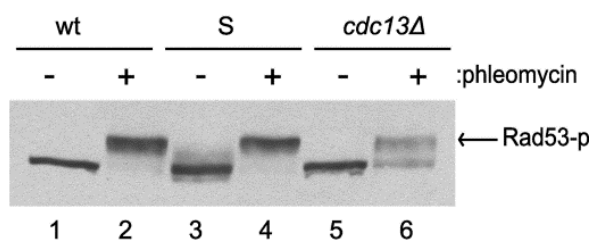

FIGURE 1: Mec1-dependent Rad53 phosphorylation is defective in $c d c 13 \Delta$ cells. (A) Terminal chromosomal regions were amplified by PCR and sequenced. Telomeric DNA (in bases) present on the amplified fragments is indicated. A total of 17 independent sequences were obtained, with two of them ending in the subtelomeric $Y^{\prime}$ element. (B) Exponentially growing wild-type

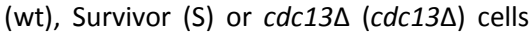
were left untreated or were treated with phleomycin for $2 \mathrm{~h}$. Protein extracts were prepared and analyzed by western blotting with an anti-Rad53 antibody. (C) As in (B) except that cells also lacked the TEL1 gene as indicated in the Survivors (S) and Cdc13independent $(c d c 13 \Delta)$ cells. Cells were left untreated or were treated with phleomycin for $2 \mathrm{~h}$.

branch of the sensor kinase pathway. We therefore constructed Cdc13-independent survivor strains that lacked Tel1p and assessed the degree of Rad53p phosphorylation induced by phleomycin. While survivor strains with a tel1 $\Delta$ allele are able to strongly phosphorylate Rad53p (Fig. 1C, lane 4), Cdc13-independent survivors harbouring the tel1 $\Delta$ allele were unable to do so (Fig. 1C, lane 8).

As DSBs are usually recognized rather efficiently, we wondered whether telomeres in Cdc13-independent cells had developed an alternative, telomeric DNA-independent capping mechanism or whether they were simply ignored by the DNA damage/repair machinery. To address this, we used fluorescence microscopy to visualize proteins involved in the recognition and repair of DNA DSBs. DNA end resection at DSB generates single-stranded DNA (ssDNA) that is rapidly bound by the RPA complex, and the focal localization of RPA on DNA damage sites can be visualized in living cells via YFP-tagged Rfa1p [39]. As a positive control, we treated cells with the radiomimetic drug zeocin and, as expected, zeocin induced the formation of Rfa1-YFP foci in wild-type cells (Fig. 2A, B). Strikingly, in Cdc13independent survivor cells, Rfa1-YFP foci were readily detectable, even in the absence of zeocin treatment (Fig. 2).

Quantification indicates that ssDNA is present in more than $80 \%$ of unperturbed $\mathrm{S} / \mathrm{G} 2$ cells and more than $50 \%$ of cells in G1. As an additional read-out for the presence of DNA damage recognition, we carried-out the same analysis with Rad52-YFP. In untreated wt (wild type) cells, Rad52YFP foci are rare and zeocin treatment increased the fraction of cells displaying Rad52-YFP foci to about 80-90 \% (Fig. 2). Again in stark contrast with these results, the majority of untreated Cdc13-independent cells already had Rad52YFP foci and there was no detectable increase upon zeocin treatment.

If uncapped telomeres were the source of Rfa1-YFP foci in Cdc13-independent survivor cells, they should rapidly disappear following reintroduction of CDC13. We thus transformed Cdc13-independent survivor cells with a plasmid that contained the wt $C D C 13$ gene and assessed telomeric restriction fragments and RPA-foci. TRF patterns in Cdc13-independent survivor cells with Cdc13p reexpressed reverted to a typical survivor pattern (compare Fig. 2C with Fig. S1) and the appearance of Rfa1-YFP foci reverted back to a level observed in CDC13 wt cells (Fig. 2D). These results indicate that re-establishing a Cdc13dependent capping system in $c d c 13 \Delta$ cells eliminates the presence of the detected DNA damage and suggest that telomere uncapping is indeed the source of the RFA and Rad52p foci in cdc13s mutants. Thus, in Cdc13independent survivors, uncapped and resected telomeres persist throughout the cell cycle and are bound by proteins that would allow ongoing DNA repair. However, Mec1mediated DNA damage signalling is by and large abrogated, allowing for cell divisions to continue and hence, culture growth.

\section{A functional checkpoint is incompatible with growth in the absence of CDC13}

The data described above indicate that uncapped telomeres and apparent DNA damage foci are constitutively present in a large fraction of the Cdc13-independent cells. Given the virtual absence of DNA damage signalling, we considered that inactivation of Mec1-mediated checkpoint signalling could have been caused by reduced or dysregulated DNA resection. To test this, an $\mathrm{HO}$ endonucleaseinduced DSB was created in cells in such a way that no homologous sequences for recombinational repair were present next to the break. The rate of DNA resection next to the $\mathrm{HO}$ site was monitored by denaturing slot blot analysis using a probe complementary to the processed DNA strand [40].

In this assay, signal loss for the resected strand was very similar in $C D C 13$ cells and cells that harboured a cdc13A allele (Fig. S3A, S3B). As an additional assay for 
A
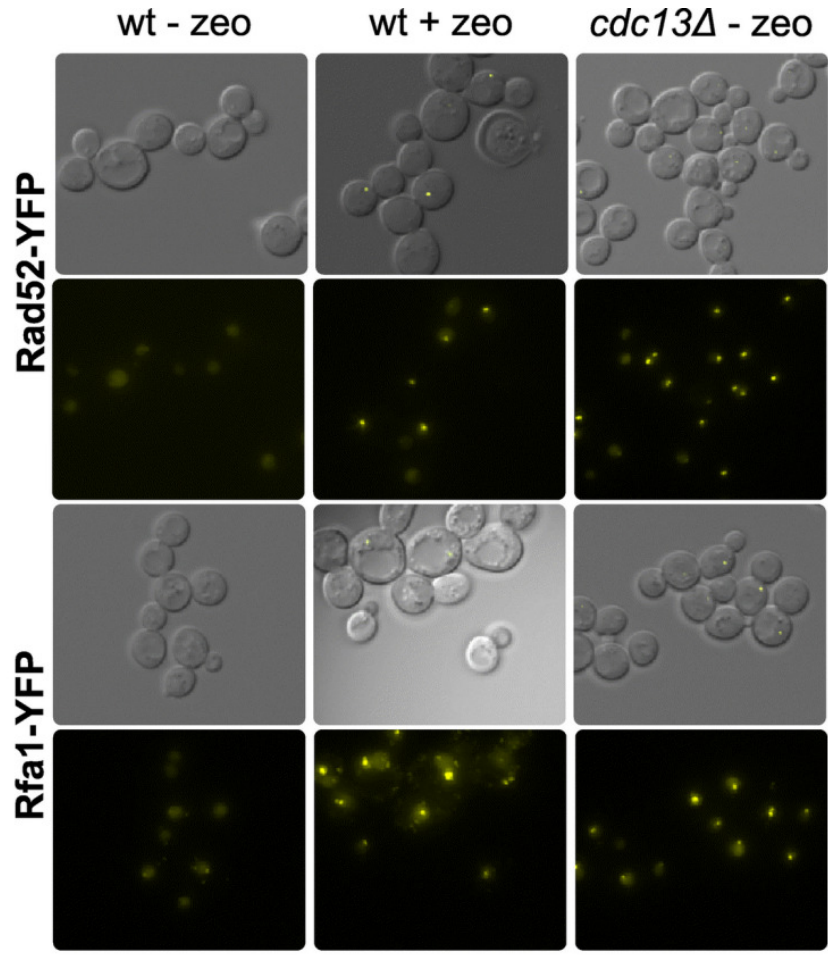

\section{DIC+YFP}

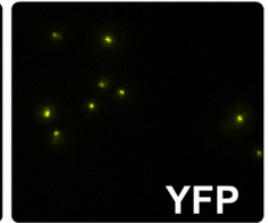

B
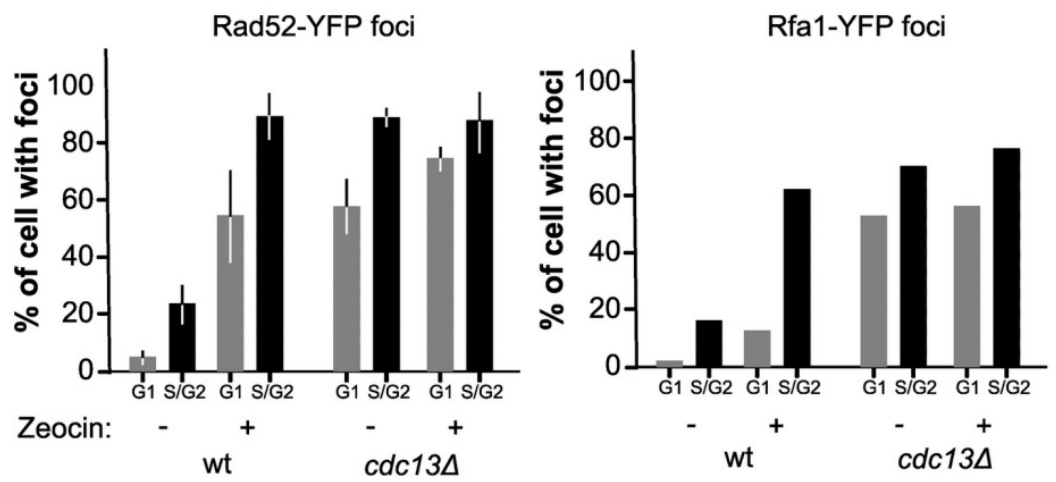

C

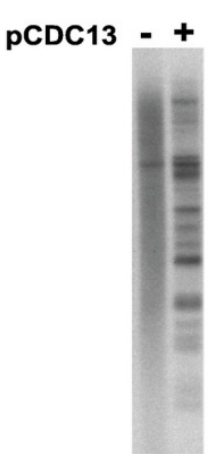

D

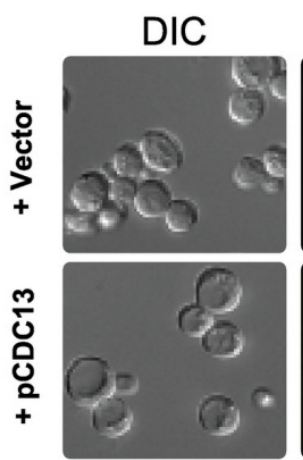

\section{Rfa1-YFP}
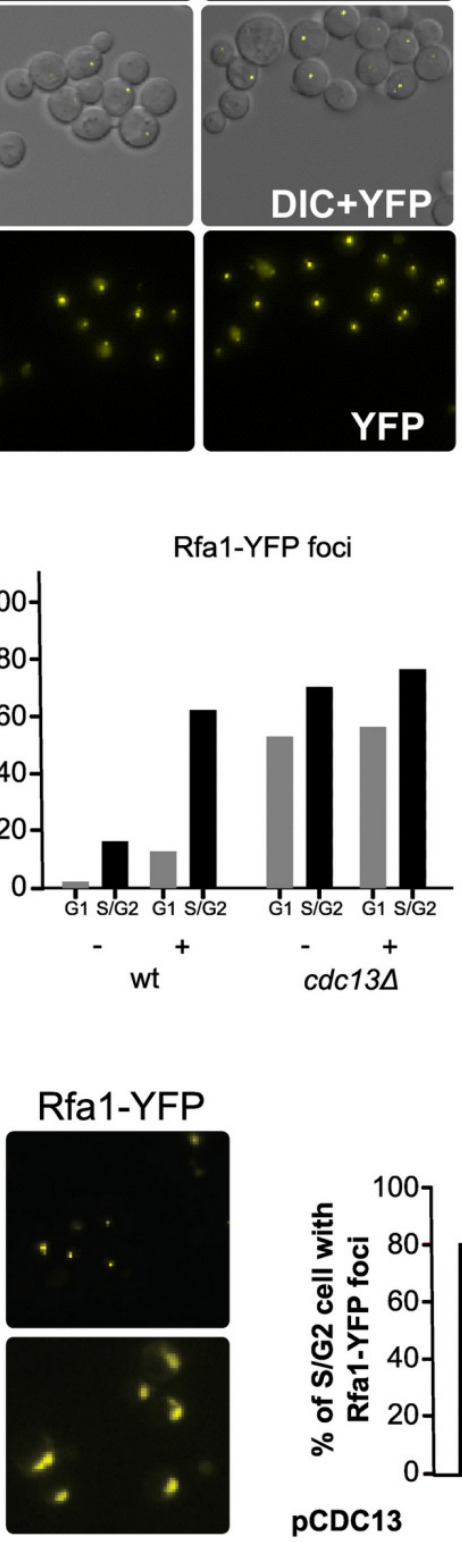

FIGURE 2: Rad52p and Rfa1p proteins form DNA damage foci in untreated cdc13 $\Delta$ cells. (A)

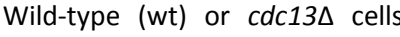
expressing the Rfa1-YFP fusion protein (RWY801) or the Rad52YFP protein (CPY821) were analysed by fluorescence microscopy untreated or treated with zeocin for $3 \mathrm{~h}$. Representative examples of the images obtained are shown. (B) Quantification of cells with foci. Cells were morphologically divided into $\mathrm{G} 1$ cells (unbudded cells) and G2M cells (large budded cells). The Rad52YFP experiment was performed in 3 independent biological replicates, and the Rfa1-YFP experiment was performed with at least 150 cells for each condition. (C) Southern blot with DNA derived from MLY122 using a telomeric DNA probe. Cells were growing in the absence of Cdc13p (lane marked -) or the wt CDC13 gene was introduced via plasmid pCDC13 (lane marked + ). Note that re-introduction of the protein $\mathrm{CDC} 13$ restores survivor type II TRF phenotype. (D) The re-expression of CDC13 eliminates the formation of Rfa1-YFP foci in cdc13 cells. Strain CPY821 was grown to become Cdc13-independent and then an empty vector or pCDC13 was introduced. Representative examples of images obtained as in (A) are shown in the left panel. Quantification of the data is shown in the right panel. $>100$ cells were counted for each sample.
DNA resection and ensuing repair, we assessed completion of mating-type switching (a process based on HR) by Southern blot analyses. As observed in the resection assay, no significant difference between wt and cells that lack Cdc13p could be detected (Fig. S3C). These physical assays show that the dynamics and efficiency of DNA end- processing and HR repair remained virtually unaffected in cells growing without Cdc13p.

An alternative hypothesis to explain the absence of Mec1p-mediated DNA damage signalling is that the checkpoint signalling proteins are themselves impaired, for instance by having acquired a mutation. In this case a forced 
re-expression of the functional wt allele of a mutated gene would cause a growth arrest in cells with perceived permanent DNA damage. We therefore cloned the wt alleles of genes encoding essential components of the Mec1checkpoint pathway into a vector that allowed a carbon source dependent expression of the protein (pGal; Fig. 3A). Twelve individual and independently generated Cdc13independent survivor strains were then transformed with those plasmids and the resulting growth behaviour was assessed on plates that induced expression of the particular gene (Gal-plates).

Remarkably, each of the twelve strains showed a growth arrest with one of the plasmids used. An example is shown in Fig. 3B, where strain MSY053 grew well on Galplates when MEC1, RAD17 or MEC3 were overexpressed, yet they failed to grow when RAD24 was overexpressed (Fig. 3B, right). These cells did grow on glucose plates (Fig. $3 B$, left) and Rad24p overexpression was readily tolerated in wt cells or regular survivor cells that contained a wt copy of $C D C 13$ (Fig. S4, top plate). The genomic RAD24 locus of strain MSY053 was sequenced and found to contain a frameshift mutation that caused a loss of function. In summary, in the 12 independently obtained Cdc13independent survivor strains, sensitivity to Rad24p expression was uncovered seven times, Mec1p six times, Rad17p two times and to Mec3p one time. These results thus further confirm that persistent telomere uncapping is sensed as DNA damage in cells without the $\mathrm{Cdc} 13$ protein and that in the absence of Cdc13p, cells can only grow with an inactivated Mec1-branch of checkpoint signalling.
Factors required for adaptation to DSBs are required for growth in the absence of Cdc13p

It has been observed that wt cells are only very rarely able to overcome a complete loss of $\mathrm{Cdc} 13 p$ but actual survival rates are unknown. We used fluctuation analyses to measure survival rates of wt cells and of cells that have overcome a telomerase deficiency (survivor cells). Only about 1 in $10^{9}-10^{10}$ cells survived an abrupt loss of Cdc13p and created a growing culture in telomerase-positive cells, whereas in cultures of survivor cells the rate is at least 1000 fold higher (Fig. 4A, [28]). This difference may be explained by the fact that telomerase-mediated telomere maintenance is not required in survivors and that upon loss of Cdc13p, cells only have to adapt to chromosome capping loss. Loss of telomeric capping is thought to have comparable effects as induction of a number of DSBs at the same time, but direct data on this is lacking.

As a consequence of telomere loss, mammalian and budding yeast cells arrest the cell cycle for prolonged periods of time before resuming growth, even in the presence of persistent damage. The latter process has been dubbed 'adaptation' and CDC5, TID1 and PTC2 genes are key elements required for adaptation to occur in yeast [37]. We therefore examined whether the generation of Cdc13independent survivors is dependent on adaptation genes. Fluctuation analyses show that survivor cells that also har-

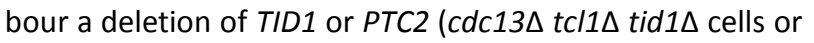
$c d c 13 \Delta t c 11 \Delta$ ptc2 $\Delta$ cells), as well as survivors that harbour an adaptation negative $C D C 5$ allele $(c d c 13 \Delta t c / 1 \Delta c d c 5$-ad cells) only generate survivors extremely rarely, at a rate of
A

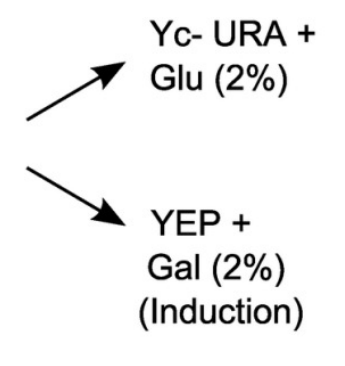

Growth test

$X X X=$ MEC3, MEC1, RAD17, RAD24

B

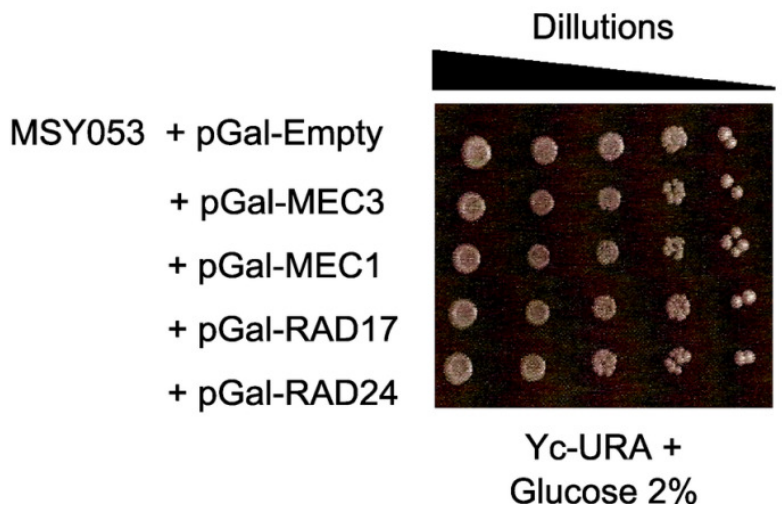

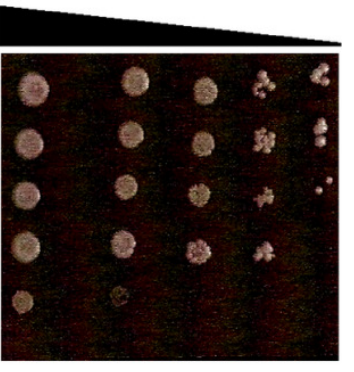

Yc-URA +

Galactose 2\%
FIGURE 3: An abrogated Mec1branch of the checkpoint pathway is required for Cdc13-independent cell growth. (A) Schematic representation of the functional complementation test: 12 independent strains of $c d c 13 \Delta$ cells were used in this experiment. Each capindependent cdc13s strain was transformed with five constructs (plasmids): pGal-MEC1, pGal-MEC3, pGal-RAD17, pGal-RAD24 or empty vector pGal-Empty as a control. Serial dilutions of cultures of the resulting strains were spotted onto YEP+ Glucose (2\%) for growth control and onto YEP+ Galactose (2\%) to induce the expression of indicated genes. (B) Cells of a Cdc13independent strain stop growing when the mutated checkpoint gene is complemented by the corresponding wild-type construct. The results shown in this figure were derived with strain MSY053 which holds a mutation in RAD24 in the genome. 
A

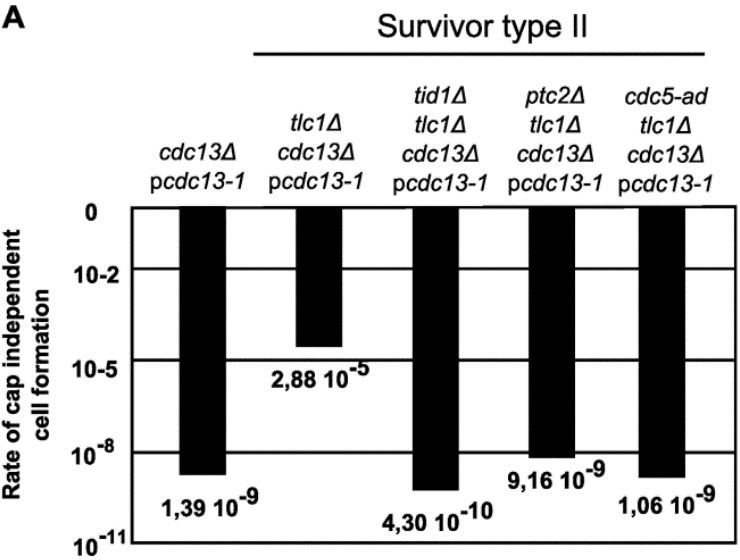

B

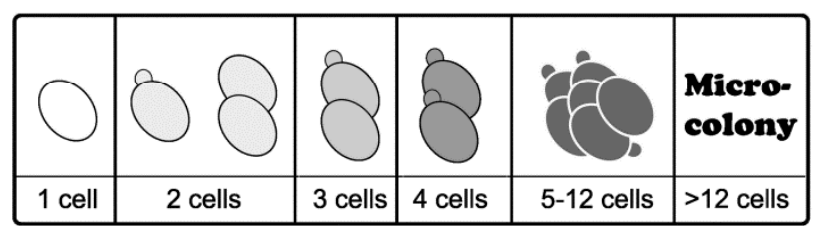

D

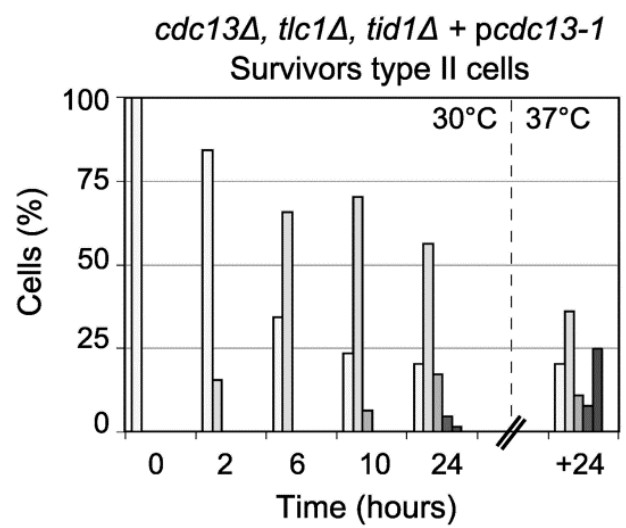

C

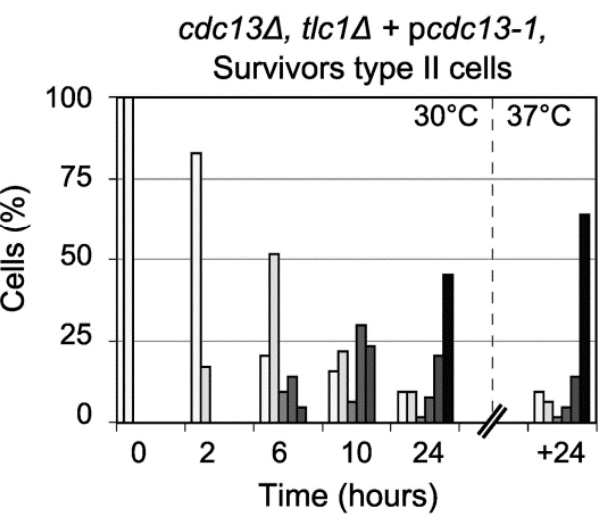

E

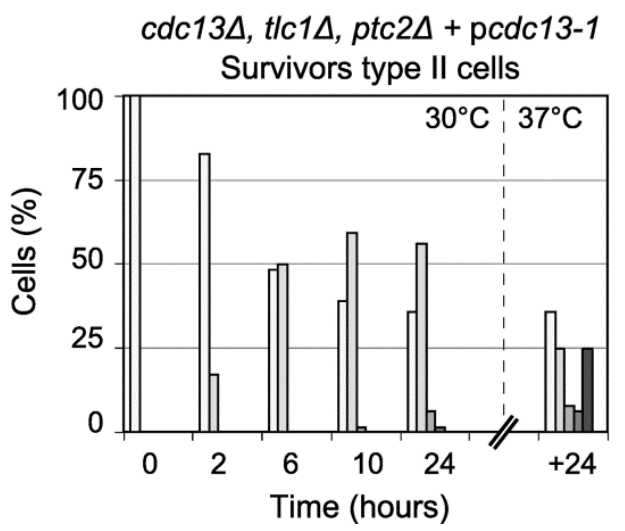

FIGURE 4: The formation of $c d c 13$-independent survivors ( $c d c 13 \Delta)$ requires DSB adaptation genes. (A) The rate of successful colony formation was calculated by fluctuation test foAr five strains: (i) telomerase positive controls, cdc13 + pcdc13-1 (VKY20), (ii) type II survivors: t/c1 1 , cdc13 + pcdc13-1 (MLY112), (iii) type II survivors harbouring a deletion of TID1: tid1 $\Delta$, t/c1 1 , cdc13 + pcdc13-1 (VKY19), (iv) type II survivors harbouring a deletion of PTC2: ptc2 $\Delta, t / c 1 \Delta, c d c 13 \Delta+$ pcdc13-1 (VKY12), or (v) type II survivors harbouring the $c d c 5-a d$ allele: $c d c 5-$ $a d, t / c 1 \Delta, c d c 13 \Delta+p c d c 13-1$ (MSY421). (B) Schematic representation of standardization for morphological classification used to analyse cell cycle progression of the strains of interest. (C) (D) (E) Single round unbudded cells (64 cells) from three strains described above (ii) (iii) (iv) were identified and arrayed on YEPD plates and incubated at $30^{\circ} \mathrm{C}$ (restrictive temperature for the cdc13-1 allele). Morphology and growth of cells were inspected microscopically at 2, 6, 10 and $24 \mathrm{~h}$ after incubation. Plates were then incubated at $37^{\circ} \mathrm{C}$ for another $24 \mathrm{~h}$. Colony morphology was recorded as outlined in (B) and results plotted as the percentage of the initial group. (C) Cell cycle progression for the survivor type II t/c1 1 , cdc13 + pcdc13-1 (MLY112); (D) and (E) cell cycle progression for both adaptation deficient mutants $\operatorname{tid} 1 \Delta, t / c 1 \Delta, c d c 13 \Delta+$ pcdc13-1 (VKY19), ptc2 $\Delta, t / c 1 \Delta, c d c 13 \Delta+$ pcdc13-1 (VKY12). 
about $5 \times 10^{-9}$ to $5 \times 10^{-10}$ (Fig. 4A). Similarly, when the morphology of cells and the generation of micro-colonies was examined in a single cell assay after inactivation of Cdc13p via a temperature upshift to restrictive temperatures, survivor cells ( $c d c 13 \Delta t c 11 \Delta+$ pcdc13-1) showed clear signs of adaptation; after $24 \mathrm{~h}$ at $30^{\circ} \mathrm{C}$, more than $50 \%$ of the cells had grown into micro-colonies of 5 cells or more and at least $60 \%$ of them became micro-colonies with more than 12 cells after another $24 \mathrm{~h}$ at $37^{\circ} \mathrm{C}$ (Fig. 4B, C). In contrast, more than $50 \%$ of adaptation-negative survivors ( $c d c 13 \Delta$ tcl1 $\Delta$ tid $1 \Delta+$ pcdc13-1 cells or $c d c 13 \Delta t c 11 \Delta$ ptc2 $\Delta$ + pcdc13-1 cells) were still single cells or small budded cells after $24 \mathrm{~h}$ at $30^{\circ} \mathrm{C}$ and only a small minority formed 5-12 cell colonies (Fig. 4D, E). Finally, none of the 64 adaptationnegative (either ptc2 $\Delta$ or tid1 $\Delta$ ) survivor cells generated a viable colony. This was expected given the very low rate determined by fluctuation tests. We conclude that the TID1, PTC2 and CDC5 genes are required in yeast for both, adaptation to persistent DNA damage after DSB induction as well as for the ability of survivor cells to generate growing colonies after the loss of telomere capping.

\section{A reversible component to adaptation to telomere un- capping}

The results thus suggest that adaptation to telomere uncapping requires known adaptation genes, that telomere

A

Growth at $23^{\circ} \mathrm{C}$ loss of pcdc13-1

\section{Reintroduction of pCDC13}

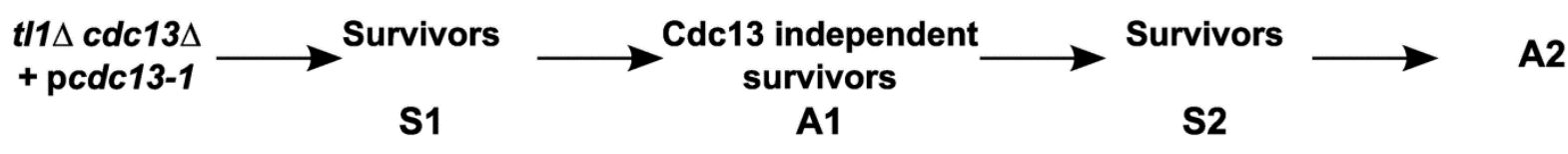

B

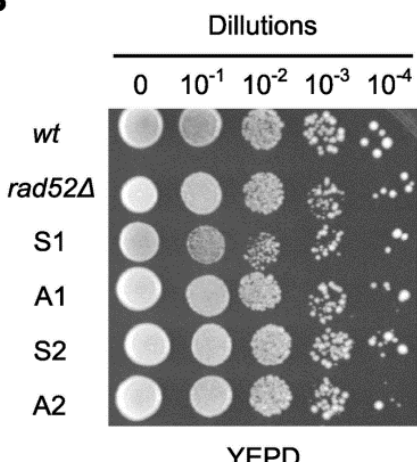

YEPD

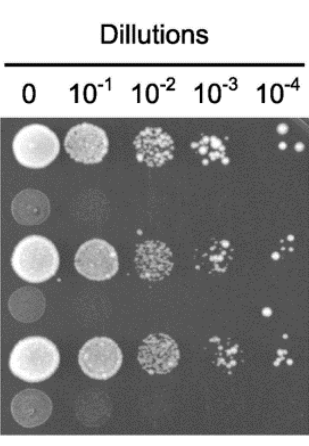

HU 50mM
C

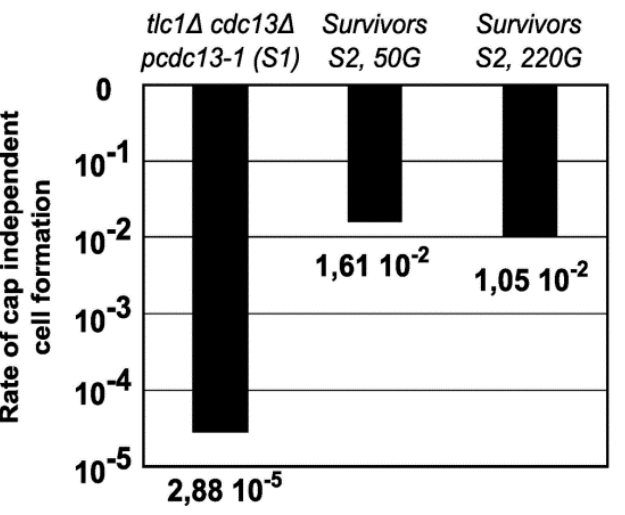

D

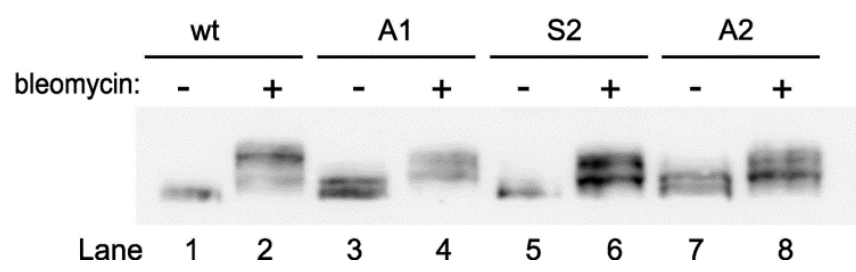

FIGURE 5: The process of generating Cdc13-independent survivors (cdc13 $\Delta$-cells) comprises a reversible component. (A) Schematic representation of the procedure used to generate S2 survivors and second generation $c d c 13 \Delta-\mathrm{A} 2$ of Cdc13-independent survivors. S1 survivors and $c d c 13 \Delta$-A1 were generated as described in Fig. 1 . S2 survivor cells were derived from $c d c 13 \Delta-\mathrm{A} 1$. These cells were grown for up to 220 generations (220G) after transformation with the plasmid carrying the $c d c 13-1$ allele. For $c d c 13 \Delta-\mathrm{A} 2$ cells (MLY123), the loss of the pCDC13 plasmid was verified by growing cells on FOA synthetic medium. (B) Cells identified with symbols as in (A) were spotted onto YEPD plates with or without hydroxyurea (HU) and incubated for $72 \mathrm{~h}$ at $23^{\circ} \mathrm{C}$. A haploid rad52A strain was used as control for HU sensitivity. (C) Rate of successful cdc13-independent cell formation (calculated by fluctuation test) for survivors S1 (MLY112) and survivors S2 (MLY122 + pcdc13-1). S2 survivors were grown for 50 or 220 generations after pcdc13-1 introduction and before the fluctuation test for plasmid loss was performed. (D) Western blot of whole cell protein extracts prepared from strains indicated with the same symbols as in (A)(top). Cell treatment with bleomycin is indicated with - and +, and the blot was probed with an anti-Rad52 antibody as in Fig. 1. 
maintenance is carried out by recombination, and that at least one gene of the DNA checkpoint signalling machinery has to be inactivated by mutation. However, it was unclear whether this adapted state, once achieved as a metabolic state, is stable and remains active in cells or whether it is reversible. In order to assess this question, we generated cells that passed through the survivor state and had adapted to Cdc13p-loss. We then re-introduced the Cdc13p capping protein into these cells to let them grow with the capping protein (see schematic in Fig. 5A). The TRF patterns of such cells changed and again became typical for survivor cells [28].

Adapted $c d c 13 \Delta$ cells were sensitive to agents causing replication stress, such as hydroxyurea (HU). However after Cdc13p re-introduction they reverted to an insensitive phenotype similar to wt and pre-adaptation survivors (Fig. $5 B,[28])$. We eventually challenged these latter cells to a Cdc13p-loss a second time. In this experiment, we call survivors before the first Cdc13-loss 'S1-cells' and those generated by re-introduction of $\mathrm{Cdc13p}$ into Cdc13independent cells 'S2-cells' (see Fig. 5A). We then compared the rates of adaptation of S1 or S2 cells by fluctuation analyses (Fig. 5C). Remarkably, even though S2 cells had been derived from adapted cells, only about $1 \%$ of them formed viable colonies after the second loss of Cdc13p. While this rate was about 1000 fold higher than that observed for the original transition of $\mathrm{S} 1$ cells to adapted cells (Fig. 4A, 5C), it still far from complete and indicated that the reintroduction of $\mathrm{Cdc} 13 p$ into adapted cells is associated with a reversion of at least part of the phenotype.

This low adaptation rate did not change with longer outgrowth of S2 cells; after 220 generations of growth in the S2 state, the rate of adaptation remained about $1 \%$ (Fig. 5C). Similar to the transition from S1 to the first adaptation state, the transition from S2 to adapted state also resulted in an increased sensitivity to hydroxyurea (HU) (Fig. 5B). However, the capacity to fully phosphorylate Rad53p did not recover after reintroduction of Cdc13p into adapted A1 cells (S2 cells; Fig. 5D, lane 6). The signalling also remained partial after the second loss of Cdc13p (Fig. $5 \mathrm{D}$, lane 8 ), as would be expected if this part of the phenotype was genetically determined. We conclude that the very low rate of colony formation after a first loss of Cdc13p from survivor cells (about $3 \times 10^{-5}$ ) can be explained by the fact that a mutation in one of the Mec1-branch checkpoint genes is required. A second Cdc13p loss after a temporary reintroduction of it still is poorly tolerated and only about one percent of cells survive, suggesting that a metabolic, non-genetic, component of the adaptation state does reverse upon introduction of $\mathrm{Cdc} 13 \mathrm{p}$.

\section{DISCUSSION}

Checkpoint adaptation was originally described as the ability of $S$. cerevisiae cells to overcome a sustained checkpoint arrest due the presence of irreparable DNA damage [4143]. Subsequently, mechanisms to abrogate a prolonged checkpoint arrest were also reported to operate in
Xenopus laevis and human cells and the well conserved genetic requirements for the process suggested a common evolutionary origin $([44,45]$; see below). Although cells undergoing checkpoint adaptation almost invariantly die in subsequent cell cycles, owing to rampant genome instability, some cells do divide a limited number of times. However, it remained unclear how these cells managed to pass through the cell divisions and whether checkpoint abrogation is permanent or temporary. A conceptually similar situation arises in the etiology of malignant human cells. Current evidence strongly suggests that precancerous cells, very early on, undergo a phase of high level genome instability that is due to dysfunctional telomeres [46]. Once this serious bottleneck is overcome, cancerous cells have invariably activated a mechanism to maintain telomeric repeats, which is almost always achieved by a reactivation of telomerase, and they have inactivated genome surveillance mechanisms, in most cases at least including TP53 [34]. Experimental setups that allow a systematic study of the chain of events happening in human cells when passing from normal to pre-cancerous therefore promise to yield invaluable insights into the very early etiology of cellular transformation.

Budding yeast cells maintain telomeres via a constitutively active telomerase, but cells can be engineered to lose telomerase and thus, in this respect, phenotypically become more like human somatic cells [1]. For example, yeast cells without telomerase endure telomere shortening eventually leading to crisis and growth arrest, when at least some telomeres are dysfunctional [1]. Yeast survivor cells are defined as the fraction of telomerase negative yeast cells that overcome this short telomere crisis by replenishing telomeric repeats by HR. Previously, we showed that again only a fraction of such survivor cells are able to survive a loss of functional telomere capping as well, generating so called cap-independent survivors [28]. These latter cells are able to divide but are very sensitive to genotoxic compounds and they have a significantly reduced ability for DNA damage signalling.

The characteristics of the cap-independent survivor cells reported here are similar in several ways to early transformed human cells. Most significantly, capindependent survivors have acquired mutations in at least one gene in the canonical DSB signalling pathway, which is governed by Mec1p in yeast (ATR in humans; Fig. 3, S4). As a consequence, the downstream effectors for cell cycle arrest are not activated and cell divisions continue even in the continued presence of DNA damage. The fact that cells stopped growing when we re-established the pathway by transforming cells with wt copies of the mutated genes demonstrates that these continued cell divisions are indeed dependent on an abrogated damage signalling pathway (Fig. 3). A conceptually similar effect has been reported in human and mouse cancer cells in which the reversion of a mutated TP53 allele leads to a re-establishment of genome surveillance mechanisms and tumour cell death [47-49]. As in human cancer cells, the physical recognition of a DSB and its actual repair appear virtually unaffected in the cap-independent yeast cells (Figs. S3). Remarkably, a 
very high level of DNA damage foci are observed in capindependent survivor cells in any phase of the cell cycle (Fig. 2). In normal cells, this level of DNA damage would invariably lead to a prolonged cell cycle arrest in G2/M [39] However, this is not the case in Cdc13p-independent cells due to the loss of damage signalling.

The results strongly suggest that the DNA damage foci detected in these experiments are on chromosome ends and that DNA repair activity, i.e. HR, is ongoing on those sites. This idea is supported by the observations that a significant fraction of telomeric restriction fragments cloned from these cells does not contain any telomeric sequences anymore (Fig. 1). Those sites are therefore indistinguishable from any other DSB in the genome and are presumably recognized as such. Furthermore, when we introduced one additional specific DSB via an induced endonucleolytic cleavage, that DSB gets resected and eventually repaired via HR with similar kinetics to normal cells (Fig. S3). Thus, DNA damage in these cells is recognized by the DNA repair machinery and HR particularly, can be active.

The reason why $\mathrm{Cdc} 13 p$-independent cells remain viable and the cultures grow with abundant DNA damage foci present is that in these cells, telomeric DNA (either subtelomeric complex repeats or terminal short repeats) becomes amplified and chromosome ends eventually are all composed of extensive head to tail arrays of repeated elements [1]. Therefore, the genome remains, by and large, intact and functional, even though significant amounts of terminal DNA may be lost due to end-degradation from these repeated elements.

A similar dynamic behaviour of DNA adjacent to telomeres has also been described in Drosophila melanogaster [50]. In this organism, chromosomes end with telomere specific retroelements, i.e. arrays of repeated and complex DNA elements, and there are neither short direct repeats nor evidence for a telomerase enzyme. As expected therefore, the terminal elements suffer gradual sequence losses with each cell division. However, the relatively limited overall losses are confined to the most distal parts of the chromosomes and these are balanced by the occasional acquisition of large repeat units [50]. Despite this very dynamic telomere maintenance mechanism, the genome in $D$. melanogaster cells remains intact, as it does in the capindependent yeast cells reported here.

During these studies of cap-independent yeast cells, we further discovered that genes required for checkpoint adaptation, namely CDC5Wt, PTC2 and TID1/RDH54, are also required for generating dividing survivor cells that harbour a non-functional $c d c 13$ allele (Fig. 4). Ptc2p is a type $2 C$ phosphatase and has been described as being directly involved in deactivating the DNA damage signalling pathway by dephosphorylating proteins, in particular Rad53p [51]. The cellular regulation of this phosphatase and how its checkpoint-abrogating activity is induced remain unclear however. The Tid1/Rdh54p protein is involved in DSB repair, by mitotic and meiotic HR, and it is itself phosphorylated by the Mec1p branch of the checkpoint signalling pathway after DNA damage [52]. The precise roles for
Tid1/Rdh54p in checkpoint adaptation are poorly defined though.

Consistent with the above, the adaptation characteristic cdc5-ad allele [42] caused an indistinguishable phenotype as the losses of Tid1/Rdh54p or Ptc2p. Although the precise roles of these checkpoint adaptation genes in allowing survivor cells to recover from inactivating Cdc13p are not known, they are not simply suppressors of the ts phenotype conferred by the cdc13-1 allele. We could not detect any differences in the temperature dependent growth characteristics between $c d c 13-1$ cells as compared to $c d c 13-1$ tid1 $\Delta$ or $c d c 13-1$ ptc2 $\Delta$ cells (Fig. S5).

Given the importance of these above genes in checkpoint adaptation, collectively our data underscore that cap-independent growth of yeast cells relies on the ability of cells to shut off checkpoint signalling. One might have suspected that once checkpoint signalling is abrogated by a mutation in one of the essential genes of the pathway (MEC1, MEC3, RAD24, or RAD17, see Fig. 3), checkpoint adaptation may not be necessary anymore and cells would readily divide and grow in $\mathrm{Cdc} 13 \mathrm{p}$-inactivating conditions ( $37^{\circ} \mathrm{C}$ with a cdc13-1 allele). However, when we tested this idea by challenging rad 24 cells with a $\mathrm{Cdc} 13 p$-loss a second time, only a small percentage of cells succeed to become dividing cultures (Fig. 5).

An efficient generation of cap-independent cells was reported to occur in cells that were engineered to lack the $R A D 9$ gene as well as deletions of at least two additional genes involved in pathways that generate single-stranded DNA, namely SGS1 and EXO1 [29]. It is therefore tempting to speculate that checkpoint adaptation genes are required to deal with the excess single-stranded DNA that is generated after a loss of telomeric capping. This function could thus be in addition to causing the loss of phosphorylation on key checkpoint signalling proteins, but it remains unclear what this could entail. Our data therefore support the hypothesis that checkpoint adaptation might be a cancer promoting mechanism in humans and that polo-like kinases, which are required for checkpoint adaptation in yeast and human cells, could be potent anti-cancer targets [53]. Further investigation of the mechanistic details of adaptation to telomeric cap loss in yeast thus has the potential to reveal new anti-cancer targets.

Finally, Cdc13p-independent cells are sensitive to the replication-interfering drug hydroxyurea (HU), yet this sensitivity is reversed upon re-introduction of wt Cdc13p (Fig. 5) and therefore is not due to mutations in checkpoint signalling genes. In parallel, upon Cdc13p-introduction, DNA damage foci are also lost in these cells (Fig. 2). In order to explain the reversible sensitivity to $\mathrm{HU}$, we speculate that in cap-independent survivors, a limiting component of the DNA repair machinery is tied up at uncapped telomeres and a large amount of additional DNA damage very rapidly becomes toxic, because it is left unrepaired. Upon reintroduction of Cdc13p, capping is re-established, single stranded DNA at chromosome ends is lost and the cells regain full potential to deal with drug-induced DNA damage. This hypothesis predicts that sub-lethal interference with telomere capping in human cancerous cells would sensitize 
these cells to DNA damaging agents. Approaches for therapeutic uncapping are being pursued $[54,55]$ and our results suggest that a key to their success will be to combine telomere uncapping reagents with standard DNA damage treatments.

\section{MATERIAL AND METHODS}

Yeast Strains and plasmids

All strains and plasmids are presented in Supplementary Tables 1 and 2, respectively. Cdc13 $\Delta$ strains were derived from the diploid strain UCC3535 [56], in which one allele of the CDC13 gene was disrupted by the natR gene, removing coding sequences +57 to +2361 with respect to the initiation codon of $C D C 13$.

\section{Survivor and cap-independent cell generation}

Haploid MLY100 cells containing plasmid pcdc13-1 were grown at $23^{\circ} \mathrm{C}$ for approximately 150 generations and type II survivor cells were identified by Southern-blot. Individual colonies from these type II survivors were incubated on nonselective YEPD plates at $23^{\circ} \mathrm{C}$ for $48 \mathrm{~h}$. The colonies obtained were re-plated on YEPD every 48-72 $\mathrm{h}$ at gradually higher temperatures until reaching $37^{\circ} \mathrm{C}\left(28^{\circ} \mathrm{C}\right.$ for $48 \mathrm{~h}, 30^{\circ} \mathrm{C}$ for 48 $72 \mathrm{~h}$, then $34^{\circ} \mathrm{C}$ for $24-72 \mathrm{~h}$ and finally $24 \mathrm{~h}$ at $37^{\circ} \mathrm{C}$ ). The colonies obtained are passaged two times on FOA-containing plates to ensure complete loss of the plasmid pcdc13-1. These $c d c 13 \Delta$ - cells were then able to grow at all temperatures.

\section{Colony growth tests (spot dilution tests)}

Strains of interest were grown in liquid media at various temperatures (as indicated in figures) until reaching exponential growth phase $\left(\mathrm{OD}_{660 \mathrm{~nm}}=0.7-1.0\right)$. Cultures were then serially diluted in order to provide from 10 (minimum) to 100000 (maximum) cells per volume plated $(10 \mu \mathrm{l})$. After mixing and separating cells by vortexing, $10 \mu$ l aliquots of a complete dilution series ( $1 / 10$ dilution factor between spots) were spotted on petri dishes containing various selective media. The resulting plates were incubated for 72 to $150 \mathrm{~h}$ at appropriate constant temperature until single colonies were clearly visible for positive control strains.

\section{Colony growth analysis}

$5 \mathrm{ml}$ liquid cultures of strains of interest were grown at $23^{\circ} \mathrm{C}$ with continuous agitation in appropriate media (e.g. YEPD plate is used for the $c d c 13 \Delta$ strains). After the cultures reached $\mathrm{OD}_{660 \mathrm{~nm}}=0.5,100 \mu \mathrm{l}$ of the culture were spread on a marked area of a pre-heated $\left(30^{\circ} \mathrm{C}\right)$ YEPD plates. Individual round unbudded cells were arrayed on YEPD plates as quickly as possible (max. time was $15 \mathrm{~min}$ ) using a micromanipulator stage on a microscope. 16 cells were arrayed on one plate in a typical experiment, and a total of 64 cells of the same strain were arrayed. The plates with arrayed cells were then incubated at $30^{\circ} \mathrm{C}$. Morphology and growth of cells were inspected microscopically every $2 \mathrm{~h}$ and colony growth progression was evaluated by counting cells as follows:

- Round unbudded cells were scored as single cells, still in G1. - Mother cells with a bud or cells showing a dumbbell morphology were scored as 2 cells.

- Round unbudded cells attached to a mother cell with a bud were scored as 3 cells.
The plates were further incubated at $30^{\circ} \mathrm{C}$ up to $24 \mathrm{~h}$ and cells were counted again at this point. This incubation at $30^{\circ} \mathrm{C}$ was followed by incubation at $37^{\circ} \mathrm{C}$ for another $24 \mathrm{~h}$. The number of cells was again registered at this point. The plates were left at $37^{\circ} \mathrm{C}$ for another $72 \mathrm{~h}$ in order to evaluate whether complete colonies could form and photos were taken at this point.

Quantification of the rate of cdc13-independent cell generation (fluctuation test)

Yeast strains were pre-grown in $5 \mathrm{ml}$ synthetic medium lacking uracil at $23^{\circ} \mathrm{C}$ until saturation. $2 \times 10^{6}$ cells were inoculated in $5 \mathrm{ml}$ YEPD liquid medium and incubated at $30^{\circ} \mathrm{C}$ in a rotary drum with constant rotation for exactly 24 h. $10^{4}$ cells were plated on YEPD plates and one plate was incubated at $23^{\circ} \mathrm{C}$ (for viability control) and another at $37^{\circ} \mathrm{C}$ (number of capindependent cells control) for at least $72 \mathrm{~h}$. The number of well-developed colonies was counted on each plate. This procedure was performed 20 times for each strain using independent colonies for their initial culture inoculation. To calculate the adaptation rate to telomere deprotection for different strains, we used the equation proposed by Luria and Delbrück [57]:

\section{$A=\left[-\ln \left(\mathbf{N}_{0} / \mathrm{N}\right)\right] / \mathrm{M}$}

A: Adaptation rate (number of adaptation events per cell division)

$\boldsymbol{N}_{\mathbf{0}}$ : Number of experiments that resulted in 0 adapted cells (number of plates with $O$ colonies after incubation at $37^{\circ} \mathrm{C}$ ) $\boldsymbol{N}$ : Number of experiments (number of plates)

M: Number of cells entering each experiment (number of cells plated per plate)

Colonies from these type II survivors were incubated in liquid YEPD media at $23^{\circ} \mathrm{C}$ and $30^{\circ} \mathrm{C}$ until dense cultures were achieved (approximately 10 generations of growth) and then assayed for frequencies of generating $\mathrm{Cdc} 13$-independent cells by plating onto YEPD at $37^{\circ} \mathrm{C}$ and FOA plates. A total viable cell count was derived from the same cultures plated on YEPD and grown at $23^{\circ} \mathrm{C}$.

\section{Drug sensitivity assays}

For growth sensitivity assays on plates, exponentially growing cultures were 10 -fold serially diluted and spotted onto YEPD or synthetic complete plates containing $0.01 \%$ MMS or $50 \mathrm{mM}$ hydroxyurea. For acute exposure to MMS, exponentially growing cells were mock treated or treated with MMS by adding $0.01 \% \mathrm{MMS}$ to the corresponding cultures for $90 \mathrm{~min}$. Strains used for western blotting of Rad53p phosphorylation were treated or not with $5 \mathrm{\mu g} / \mathrm{mL}$ of phleomycin (phleo) of bleomycin.

\section{SDS PAGE and Western blot analysis}

Protein extracts were prepared using a modified trichloroacetic acid method and proteins were separated by $8 \%$ SDS-PAGE as described in [28]. Western blotting was performed using an in house polyclonal anti-Rad53p antibody (kindly provided by D. Durocher, Samuel Lunenfeld Research Institute, Toronto, Canada) or with a commercial polyclonal anti-Rad53p antibody (Abcam, $\mathrm{N}^{\circ}$ ab 104232, with using a 1:500 dilution) and signals were revealed using horseradish peroxidaseconjugated anti-rabbit antibodies with the enhanced chemiluminescence (ECL) detection kit (GE-Healthcare). 


\section{Terminal transferase and PCR telomere amplification}

Purified genomic DNA was treated with terminal transferase to add a poly-C tail to chromosome ends as described [58]. $100 \mathrm{ng}$ of genomic DNA were heat denatured and tailed in 10 $\mu \mathrm{l}$ of $20 \mathrm{mM}$ Tris $-\mathrm{HCl} \mathrm{pH} 7.8,50 \mathrm{mM}$ KAc, $10 \mathrm{mM} \mathrm{MgAc2}, 1$ $\mathrm{mM}$ dCTP with $1 \mathrm{U}$ of terminal deoxynucleotidyl transferase for $30 \mathrm{~min}$ at $37^{\circ} \mathrm{C}$. Following tailing, the enzyme was inactivated by incubating the samples for $10 \mathrm{~min}$ at $65^{\circ} \mathrm{C}$ and $5 \mathrm{~min}$ at $94^{\circ} \mathrm{C}$. The tailing reaction was performed in $0.2 \mathrm{ml} \mathrm{PCR}-$ tubes using a thermal cycler. By using a poly-G primer and a primer hybridizing in the subtelomeric $Y^{\prime}$ region terminal PCR products were obtained and sequenced.

\section{ACKNOWLEDGMENTS}

We thank D. Durocher (Lunenfeld Tanenbaum Res. Institute, Toronto Canada) for generously providing antibodies and J. Haber (Brandeis University, Waltham USA) for yeast strains. We are particularly indebted to M. Lisby (Copenhagen University, Copenhagen Denmark) who generously accepted RJW in his lab and in whose lab all the in vivo localization studies were performed. Members of the Wellinger lab, in particular C. Prud'homme, are thanked for valuable input and some strain constructions. This work was supported by a grant from the Canadian Institutes for

\section{REFERENCES}

1. Wellinger RJ, Zakian VA (2012). Everything you ever wanted to know about Saccharomyces cerevisiae telomeres: beginning to end. Genetics 191(4): 1073-1105.

2. de Lange $T$ (2009). How telomeres solve the end-protection problem. Science 326(5955): 948-952.

3. Wang RC, Smogorzewska A, de Lange T (2004). Homologous Recombination Generates T-Loop-Sized Deletions at Human Telomeres. Cell 119(3): 355-368.

4. van Steensel B, Smogorzewska A, de Lange T (1998). TRF2 protects human telomeres from end-to-end fusions. Cell 92(3): 401-413.

5. Gilson E, Geli V (2007). How telomeres are replicated. Nat Rev Mol Cell Biol 8(10): 825-838.

6. Hug N, Lingner J (2006). Telomere length homeostasis. Chromosoma 115(6): 413-425.

7. LeBel C, Wellinger RJ (2005). Telomeres: what's new at your end? J Cell Sci 118(Pt 13): 2785-2788.

8. McElligott R, Wellinger RJ (1997). The terminal DNA structure of mammalian chromosomes. Embo J 16(12): 3705-3714.

9. Wellinger RJ, Wolf AJ, Zakian VA (1993). Saccharomyces telomeres acquire single-strand TG1-3 tails late in S phase. Cell 72(1): 51-60.

10. Gao H, Cervantes RB, Mandell EK, Otero JH, Lundblad V (2007). RPA-like proteins mediate yeast telomere function. Nature Structural \&\#38; Molecular Biology 14(3): 208-214.

11. Grandin N, Damon C, Charbonneau M (2001). Ten1 functions in telomere end protection and length regulation in association with Stn1 and Cdc13. Embo J 20(5): 1173-1183.

12. Grandin N, Reed SI, Charbonneau M (1997). Stn1, a new Saccharomyces cerevisiae protein, is implicated in telomere size regulation in association with Cdc13. Genes Dev 11(4): 512-527.
Health Research (CIHR, grant \# 110982) and RJW holds the Canada Reserch Chair in Telomere Biology.

\section{SUPPLEMENTAL MATERIAL}

All supplemental data for this article are available online at www.microbialcell.com.

\section{CONFLICT OF INTEREST}

The authors declare no conflict of interest.

\section{COPYRIGHT}

(C) 2015 Mersaoui et al. This is an open-access article released under the terms of the Creative Commons Attribution (CC BY) license, which allows the unrestricted use, distribution, and reproduction in any medium, provided the original author and source are acknowledged.

Please cite this article as: Sofiane Y. Mersaoui, Serge Gravel, Victor Karpov, and Raymund J. Wellinger (2015). DNA damage checkpoint adaptation genes are required for division of cells harbouring eroded telomeres. Microbial Cell 2(10): 394-405. doi: 10.15698/mic2015.10.229

13. Garvik B, Carson M, Hartwell L (1995). Single-stranded DNA arising at telomeres in cdc13 mutants may constitute a specific signal for the RAD9 checkpoint. Mol Cell Biol 15(11): 6128-6138.

14. Hartwell LH, Mortimer RK, Culotti J, Culotti M (1973). Genetic Control of the Cell Division Cycle in Yeast: V. Genetic Analysis of cdc Mutants. Genetics 74(2): 267-286.

15. Booth C, Griffith E, Brady G, Lydall D (2001). Quantitative amplification of single-stranded DNA (QAOS) demonstrates that cdc13-1 mutants generate ssDNA in a telomere to centromere direction. Nucleic Acids Res 29(21): 4414-4422.

16. Nugent $\mathrm{Cl}$, Hughes TR, Lue NF, Lundblad V (1996). Cdc13p: a single-strand telomeric DNA-binding protein with a dual role in yeast telomere maintenance. Science 274(5285): 249-252.

17. Greider CW, Blackburn EH (1987). The telomere terminal transferase of Tetrahymena is a ribonucleoprotein enzyme with two kinds of primer specificity. Cell 51(6): 887-898.

18. Greider CW, Blackburn EH (1985). Identification of a specific telomere terminal transferase activity in Tetrahymena extracts. Cell 43(2 Pt 1): 405-413.

19. Watson JD (1972). Origin of concatemeric T7 DNA. Nat New Biol 239(94): 197-201.

20. Lendvay TS, Morris DK, Sah J, Balasubramanian B, Lundblad V (1996). Senescence mutants of Saccharomyces cerevisiae with a defect in telomere replication identify three additional EST genes. Genetics 144(4): 1399-1412.

21. Lundblad V, Szostak JW (1989). A mutant with a defect in telomere elongation leads to senescence in yeast. Cell 57(4): 633-643.

22. Singer MS, Gottschling DE (1994). TLC1: template RNA component of Saccharomyces cerevisiae telomerase. Science 266(5184): 404-409.

23. Lundblad V, Blackburn EH (1993). An alternative pathway for yeast telomere maintenance rescues est1- senescence. Cell 73(2): 347-360. 
24. Teng SC, Zakian VA (1999). Telomere-telomere recombination is an efficient bypass pathway for telomere maintenance in Saccharomyces cerevisiae. Mol Cell Biol 19(12): 8083-8093.

25. Le S, Moore JK, Haber JE, Greider CW (1999). RAD50 and RAD51 define two pathways that collaborate to maintain telomeres in the absence of telomerase. Genetics 152(1): 143-152.

26. Zubko MK, Lydall D (2006). Linear chromosome maintenance in the absence of essential telomere-capping proteins. Nature Cell Biology 8(7): 734-740.

27. Petreaca RC, Chiu H-C, Eckelhoefer HA, Chuang C, Xu L, Nugent $\mathrm{Cl}$ (2006). Chromosome end protection plasticity revealed by Stn1p and Ten1p bypass of Cdc13p. Nature Cell Biology 8(7): 748-755.

28. Larrivee M, Wellinger RJ (2006). Telomerase- and cappingindependent yeast survivors with alternate telomere states. Nat Cell Biol 8(7): 741-747.

29. Ngo H-P, Lydall D (2010). Survival and Growth of Yeast without Telomere Capping by Cdc13 in the Absence of Sgs1, Exo1, and Rad9. PLoS genetics 6(8): e1001072.

30. Bryan TM, Englezou A, Dalla-Pozza L, Dunham MA, Reddel RR (1997). Evidence for an alternative mechanism for maintaining telomere length in human tumors and tumor-derived cell lines. Nat Med 3(11): 1271-1274.

31. Bryan TM, Englezou A, Gupta J, Bacchetti S, Reddel RR (1995). Telomere elongation in immortal human cells without detectable telomerase activity. Embo J 14(17): 4240-4248.

32. McEachern MJ, Haber JE (2006). Break-induced replication and recombinational telomere elongation in yeast. Annu Rev Biochem 75(111-135.

33. Henson JD, Cao Y, Huschtscha LI, Chang AC, Au AY, Pickett HA Reddel RR (2009). DNA C-circles are specific and quantifiable markers of alternative-lengthening-of-telomeres activity. Nat Biotechnol 27(12): 1181-1185.

34. Hanahan D, Weinberg RA (2011). Hallmarks of cancer: the next generation. Cell 144(5): 646-674.

35. Lydall D, Weinert T (1995). Yeast checkpoint genes in DNA damage processing: implications for repair and arrest. Science 270(5241): 1488-1491.

36. Pellicioli A, Lucca C, Liberi G, Marini F, Lopes M, Plevani P, Romano A, Di Fiore PP, Foiani M (1999). Activation of Rad53 kinase in response to DNA damage and its effect in modulating phosphorylation of the lagging strand DNA polymerase. EMBO J 18(22): 6561-6572.

37. Harrison JC, Haber JE (2006). Surviving the breakup: the DNA damage checkpoint. Annu Rev Genet 40(209-235.

38. Melo JA, Cohen J, Toczyski DP (2001). Two checkpoint complexes are independently recruited to sites of DNA damage in vivo. Genes Dev 15(21): 2809-2821.

39. Lisby M, Barlow JH, Burgess RC, Rothstein R (2004). Choreography of the DNA Damage ResponseSpatiotemporal Relationships among Checkpoint and Repair Proteins. Cell 118(6): 699-713.

40. Sugawara N, Haber JE (1992). Characterization of double-strand break-induced recombination: homology requirements and singlestranded DNA formation. Mol Cell Biol 12(2): 563-575.

41. Lee SE, Moore JK, Holmes A, Umezu K, Kolodner RD, Haber JE (1998). Saccharomyces Ku70, mre11/rad50 and RPA proteins regulate adaptation to G2/M arrest after DNA damage. Cell 94(3): 399-409.
42. Toczyski DP, Galgoczy DJ, Hartwell LH (1997). CDC5 and CKII control adaptation to the yeast DNA damage checkpoint. Cell 90(6): 1097-1106.

43. Sandell LL, Zakian VA (1993). Loss of a yeast telomere: arrest, recovery, and chromosome loss. Cell 75(4): 729-739.

44. Syljuasen RG, Jensen S, Bartek J, Lukas J (2006). Adaptation to the Ionizing Radiation-Induced G2 Checkpoint Occurs in Human Cells and Depends on Checkpoint Kinase 1 and Polo-like Kinase 1 Kinases. Cancer Research 66(21): 10253-10257.

45. Yoo HY, Kumagai A, Shevchenko A, Shevchenko A, Dunphy WG (2004). Adaptation of a DNA replication checkpoint response depends upon inactivation of Claspin by the Polo-like kinase. Cell 117(5): 575588.

46. De Lange T (2005). Telomere-related genome instability in cancer. Cold Spring Harb Symp Quant Biol 70:197-204.

47. Yu X, Vazquez A, Levine AJ, Carpizo DR (2012). Allele-specific p53 mutant reactivation. Cancer cell 21(5): 614-625.

48. Xue W, Zender L, Miething C, Dickins RA, Hernando E, Krizhanovsky V, Cordon-Cardo C, Lowe SW (2007). Senescence and tumour clearance is triggered by p53 restoration in murine liver carcinomas. Nature 445(7128): 656-660.

49. Ventura A, Kirsch DG, McLaughlin ME, Tuveson DA, Grimm J, Lintault L, Newman J, Reczek EE, Weissleder R, Jacks T (2007). Restoration of p53 function leads to tumour regression in vivo. Nature 445(7128): 661-665.

50. Pardue ML, DeBaryshe PG (2003). Retrotransposons provide an evolutionarily robust non-telomerase mechanism to maintain telomeres. Annu Rev Genet 37:485-511.

51. Leroy C, Lee S, Vaze M, Ochsenbien F, Guerois R, Haber J, Marsolierkergoat M (2003). PP2C Phosphatases Ptc2 and Ptc3 Are Required for DNA Checkpoint Inactivation after a Double-Strand Break. Molecular Cell 11(3): 827-835.

52. Ferrari $M$, Nachimuthu BT, Donnianni RA, Klein $H$, Pellicioli A (2013). Tid1/Rdh54 translocase is phosphorylated through a Mec1and Rad53-dependent manner in the presence of DSB lesions in budding yeast. DNA Repair (Amst) 12(5): 347-355.

53. Strebhardt K (2010). Multifaceted polo-like kinases: drug targets and antitargets for cancer therapy. Nature reviews Drug discovery 9(8): 643-660.

54. Mender I, Gryaznov S, Dikmen Z, Wright WE, Shay JW (2014). Induction of Telomere Dysfunction Mediated By the Telomerase Substrate Precursor 6-Thio-2'-Deoxyguanosine. Cancer Discovery 5(1): 82-95.

55. Patry C, Bouchard L, Labrecque P, Gendron D, Lemieux B, Toutant J, Lapointe $E$, Wellinger $R$, Chabot $B$ (2003). Small interfering RNAmediated reduction in heterogeneous nuclear ribonucleoparticule A1/A2 proteins induces apoptosis in human cancer cells but not in normal mortal cell lines. Cancer Res 63(22): 7679-7688.

56. Wellinger RJ, Ethier K, Labrecque P, Zakian VA (1996). Evidence for a new step in telomere maintenance. Cell 85(3): 423-433.

57. Luria SE, Delbruck M (1943). Mutations of Bacteria from Virus Sensitivity to Virus Resistance. Genetics 28(6): 491-511.

58. Forstemann K, Hoss M, Lingner J (2000). Telomerase-dependent repeat divergence at the 3 ' ends of yeast telomeres. Nucleic Acids Res 28(14): 2690-2694. 